\title{
Leukocyte inflammatory phenotype and function in migraine patients compared with matched non- migraine volunteers: A pilot study
}

Hongtao Li ( $\sim$ Hongtao.li@smwc.edu )

Saint Mary of the Woods College

Qiang Fu

Binzhou Medical University

Kamaira Philips

University of North Carolina at Chapel Hill

Yufei Sun

Binzhou Medical University

Keturah R. Faurot

University of North Carolina at Chapel Hill

\section{Susan A. Gaylord}

University of North Carolina at Chapel Hill

John Douglas Mann

University of North Carolina at Chapel Hill

\section{Research Article}

Keywords: Migraine, inflammation, autoimmunity, Monocytes, T cells

Posted Date: January 28th, 2022

DOI: https://doi.org/10.21203/rs.3.rs-1239297/v1

License: (9) This work is licensed under a Creative Commons Attribution 4.0 International License.

Read Full License 


\section{Abstract}

Background: Migraine is a neurological condition characterized by chronic inflammation. However, not much is known about the potential role of peripheral blood immune cells in the pathophysiology of migraine.

Methods: We investigated the status of peripheral blood immune cells of 15 adults with frequent episodic migraines recruited chronologically from a Randomized Clinical Trial (RCT) on Nutrition for Migraine (NCCIH 5R01AT007813-05) and 15 non-migraine, healthy volunteers (control) matched by age, gender, and Body Mass Index (BMI).

Continuous variables were presented as means \pm standard deviation, and comparisons between patients and healthy volunteers were performed with paired sample t-tests. Statistical analysis was performed using SPSS Statistics for Window, Version 17.0 (SPSS Inc., Chicago, IL). Fluorescence-Activated Cell Sorting (FACS) data were processed using FlowJo software (Ashland, OR: Becton, Dickenson and Company; 2019).

Results: We observed that migraineurs had significantly higher percentages of classical monocytes $\left(\mathrm{CD} 14^{++} \mathrm{CD} 16^{-}\right)$and a significantly lower percentage of non-classical monocytes $\left(\mathrm{CD} 14^{+} \mathrm{CD} 16^{++}\right)$in blood circulation, compared to the control group. And the mean fluorescence intensity (MFI) level of CD36 on monocyte was significantly lowered in the migraine group. Migraineurs also showed a significantly lower percentage of blood $\mathrm{CD} 3^{+} \mathrm{CD} 4^{+}$helper $\mathrm{T}$ cells and $\mathrm{CD} 4^{+} \mathrm{CD} 25^{+}$regulatory $\mathrm{T}$ cells, compared to controls. Both $\mathrm{CD} 4^{+}$and $\mathrm{CD} 8^{+} \mathrm{T}$ cells displayed lower expression (MFI) of integrin CD18 in migraineurs vs. controls.

Conclusions: Our results demonstrated that migraine is associated with dysregulated peripheral immune homeostasis that may play a role in its pathophysiology.

\section{Background}

Migraine is a major public health problem afflicting over $16 \%$ of women, $7 \%$ of men, and $12 \%$ of the total adult US population and costing billions in health care utilization [1, 2]. Inflammation has long been considered a risk factor in migraine pathogenesis [3, 4]. Examples of elevated inflammatory biomarkers, including fibrinogen and $C$ reactive protein (CRP), have been reported in migraine pathology [5-7]. In 2001, Kemper et al. reviewed 45 clinical studies from 1966 to 1999 and found differences in serum levels of complement, immunoglobulin, histamine, cytokines, and immune cells (monocyte and polymorphonuclear leukocytes) between migraineurs and volunteers without migraine. However, the findings in the various studies were inconsistent and conflicting with each other in many cases $[8,9]$, indicating a need for further investigation into the role of immune system dysfunction in migraineurs.

Given this emerging link between inflammation and migraine pathogenesis, identification of leukocyte surface antigens could potentially serve as biomarkers to help with diagnosis. In 2006, Du and colleagues 
reported that the genes significantly up-regulated by migraine were mostly from platelet/monocytes, while others were from PMNs, $\mathrm{CD} 4^{+}, \mathrm{CD} 8^{+} \mathrm{T}$ cells, and NK cells [10]. Research has also shown that lymphotoxin alpha (or tumor necrosis factor-beta) and a-fodrin are among the seven-upregulated genes in migraine with aura, compared with healthy controls [11]. Recently, a genomic-wide analysis using whole blood of 83 migraine cases and 83 age and gender-matched non-migraine controls revealed that multiple immune-inflammatory pathways, such as functional categories of HECS, Microglia, RACTOME, and Gene ontology biological processes, were underlying the pathophysiology of the disorder [12].

Arumugam and Parthasarathy (2016) studied the autoimmune biomarkers $C D 4^{+} \mathrm{CD} 25^{+}$population, helper and suppressor $\mathrm{T}$ cell populations, observing a significantly higher $\mathrm{CD} 4^{+}$population and lower $\mathrm{CD} 8^{+} \mathrm{T}$ cell population in migraineurs, compared to healthy volunteers. Furthermore, the $\mathrm{CD} 4^{+} \mathrm{CD} 25^{+}$population was significantly lower in migraine patients compared to healthy volunteers [13], suggesting that migraine may be related to autoimmunity.

Monocytes comprise a heterogeneous population that play a vital role in immune surveillance of the central nervous system (CNS). There are at least three different subsets: classical monocytes $\left(\mathrm{CD} 14^{++} \mathrm{CD} 16^{-}\right)$, intermediate monocytes $\left(\mathrm{CD} 14^{++} \mathrm{CD} 16^{+}\right)$and non-classical monocytes $\left(\mathrm{CD} 14^{+} \mathrm{CD} 16^{++}\right)$ [14]. Waschbisch and colleagues reported that monocytes expressing FcyRIII, or CD16 ${ }^{+}$, which include both intermediate and non-classical monocytes together, were reduced in the peripheral blood and migrated to the sites of inflammation, contributing to the injury of the blood-brain barrier (BBB) in CNS autoimmune diseases such as multiple sclerosis (MS) [15]. The research literature has reported the patrolling behavior of the non-classical monocyte subset [16-18] and the activation of genes associated with cytoskeleton mobility [16]. CD16 ${ }^{+}$monocytes have been reported migrating to the central nervous system in MS, HIV associated neurocognitive disorder, and giant cell arteritis $[15,19,20]$. To our knowledge, there is no report showing that $\mathrm{CD} 16^{+}$monocytes could migrate to the CNS, thereby decreasing the population percentage in migraineurs' peripheral blood.

The objective of the present study was to characterize migraineurs' peripheral leukocyte surface biomarkers and ex vivo functions to determine whether our findings indicate that migraine is related to neuroinflammation and autoimmunity. We used pre-intervention/baseline samples collected from a parent randomized controlled trial (RCT) entitled "Clinical and Metabolic Effects of Altering Omega-3 and Omega-6 Fatty Acids in Migraine" funded by an NIH R01-AT007813 (2013-2018) awarded to investigators at the University of North Carolina (UNC) at Chapel Hill [2]. We proposed to examine the leukocyte phenotype profile and cell type function between matched non-migraine volunteers and the migraineurs' baseline data. This comparison may provide mechanistic insights and initial therapeutic strategies for targeting inflammation in migraine.

\section{Materials And Methods}

\section{Participants and ethical clearance}


Fifteen consecutive migraine patients who entered the parent R01 RCT study during 2015 and 2016 were selected to be involved in this study. Both studies received approval from UNC's Institutional Review Board and all participants provided informed consent. These subjects were matched with fifteen healthy controls who were recruited to the study from the same population from which the migraineurs were drawn, through university advertising (e.g., mass email). Ascertained via telephone screening and health history questionnaire, eligible volunteers were 18 years of age or older; without chronic pain, pregnancy, or major medical/psychiatric illness; non-smokers; not taking omega-3 supplements; and without concurrent illness. Volunteers were matched to migraine participants by age (10-year categories), sex, and Body Mass Index (BMI) $(<20,20-24.9,25-29.9,30-34.9,>35)$. Blood samples were obtained via phlebotomy at the UNC Clinical and Translational Research Center and were processed immediately.

\section{Peripheral whole blood staining method using BD Bioscience protocol}

Peripheral whole blood staining method using BD Bioscience protocol Following BD whole blood staining protocols [21], we chose three panels of antibodies, with each panel containing eight antibodies. Table 1 shows the experimental design with the intention to investigate different peripheral leukocyte populations. The antibodies used in this study included: anti-CD3 (APC-H7), anti-CD36 (PerCP-Cy5.5), anti-CD14 (V500), anti-CD16 (BV421), anti-HLA-DR (BB515), anti-CD56 (PE Cy7), anti-CD86 (APC) (BioLegend, San Diego, CA), anti-CD163 (PE) (BioLegend, San Diego, CA), anti-CD8 (v500), anti-CD4 (PerCP-Cy5.5) (BioLegend, San Diego, CA), anti-CD25 (BB515), anti-CD18 (PE), antiCD49d (APC), anti-CD11c (BV510), anti-CD123 (BV421), anti-CD19 (PE-Cy7), and anti-CD80 (PE). All antibodies were purchased from BD Bioscience except where stated otherwise. Briefly, appropriate volumes of fluorochrome-conjugated antibody were added to $100 \mu \mathrm{L}$ of whole blood and incubated 15 to 30 minutes at room temperature. Then, the erythrocytes were lysed, and the samples were washed, fixed, and analyzed within about 24 hours. Data were collected with FACS CANTO II (BD Biosciences) and analyzed using FlowJo software (Tree Star, Inc., Ashland, OR).

\section{Peripheral blood mononuclear cells (PBMC) isolation, stimulation, and supernatant collection}

PBMCs were isolated from freshly collected human blood samples following density gradient centrifugation over Ficoll-Hypaque density gradient. Briefly, a diluted cell suspension was carefully layered over Ficoll-Hypaque in a conical tube without disturbing the interface, centrifuged at $1500 \mathrm{rpm}$ for 30 minutes at room temperature with the brake off. The mononuclear cell layer was at the interphase. The RBC and platelets were washed and a cell counting procedure was performed by $\mathrm{TC}^{\mathrm{T}} \mathrm{T}^{\mathrm{T}}$ Automated Cell Counter (BIO-RAD, Hercules, CA).

In vitro stimulations of one million PBMCs per well with $100 \mathrm{ng} / \mathrm{ml}$ lipopolysaccharide (LPS) for 24 hours were set up in a 6-well culture plate. After stimulation, supernatants were collected for cytokines analysis.

\section{Multiplex measurement of cytokines}


Nine cytokine (TNF-a, IL-6, IL-10, IL-1ß, IFN-y, IL-4, IL-17a, IL-12 p70, and IL-21) levels in PBMC supernatants from pre- and post-LPS 24 hours of stimulations were analyzed using R\&D multiplex analysis system at the university's Cytokine \& Biomarker Analysis Facility Center.

\section{Cell gating strategies}

For monocyte gating, neutrophils, NK cells, B cells, and T cells were successively excluded following the strategy by Mukherjee et al [22]. For T cell gating, subsets were chosen based on conventional bivariate scatterplots of side scatter signal and $\mathrm{CD} 3^{+}, \mathrm{CD} 4^{+} \mathrm{T}$ cells, $\mathrm{CD} 8^{+} \mathrm{T}$ cells, and $\mathrm{CD} 4^{+} \mathrm{CD} 25^{+} \mathrm{T}$ cells subsets.

\section{Statistical analysis}

This study presented continuous variables as means \pm standard deviation, and comparisons between patients and healthy volunteers were performed with paired sample t-tests. Our statistical analysis was performed using SPSS Statistics for Window, Version 17.0 (SPSS Inc., Chicago, IL). FluorescenceActivated Cell Sorting (FACS) data were processed using FlowJo software (Ashland, OR: Becton, Dickenson and Company; 2019). Cytokine multiplex data were processed using Stata (StataCorp. 2017. Stata Statistical Software: Release 15. College Station, TX: StataCorp LLC.).

\section{Results}

\section{Descriptive statistics}

A total of 30 subjects, 15 migraine patients who were recruited from the parent study described above, and 15 control individuals matched by gender, age and Body Mass Index (BMI), participated in this study to control the confounding factors. Their demographic comparisons are listed in Table 2. As expected, $80 \%$ were female, and the mean ( \pm standard deviation) age was $39.3^{ \pm} 12.2$ in the migraine sample, and $39.7^{ \pm} 12.2$ in the controls. BMI means were $27.2^{ \pm} 4.6$ and $27.4^{ \pm} 4.8$ in migraine and control groups, respectively.

The 15 migraine patients' pain information, including headache, comorbid pain, with or without aura, whether it meets chronic migraine criteria or not, and medication overuse information are provided in the appendix table. The number of migraines in 30 days was 11.2 \pm 5.7 days, versus the number of headaches in 30 days was $18.6 \pm 7.7$ days. About $53 \%$ of the patients meet chronic migraine criteria, which is headache occurring on 15 or more days/month for more than three months, which, on at least eight days/month, has the features of migraine headache. Eight out of 15 patients (53\%) meet the criteria for overuse of any pain medication.

$\mathrm{CD} 14^{+} \mathrm{CD}_{16}{ }^{++}$monocytes were lowered, while CD14 ${ }^{++} \mathrm{CD}_{16}{ }^{-}$monocytes were higher in the migraineurs' peripheral blood, compared with the matched control group. 
Migraine is an inflammatory disease $[3,4]$, and non-classic $\mathrm{CD} 14^{++} \mathrm{CD} 16^{+}$monocytes are associated with increased systemic inflammation [22]. To examine whether migraine patients have altered blood monocytes, we analyzed the peripheral blood classic and non-classic monocytes in migraineurs and matched control group using flow cytometry. In PBMCs single cells population, we removed NK and T cells, and then divided the HLA-DR ${ }^{+}$population into three subgroups and analyzed by CD14 and CD16 expression strength (Fig. 1A). We found that the non-classical monocyte percentage (7.49 \pm 2.43 ) (Fig. 1B) was lower in the migraine group compared with the control group, $(12.4 \pm 2.53)(* * \mathrm{P}<0.01)$. In contrast, the percentage of classical monocytes $\left(\mathrm{CD} 14^{++} \mathrm{CD} 16^{-}\right)$was $78.74 \pm 8.33 \%$ in the control group and $83.67 \pm 4.85 \%$ in the migraine group ( $\mathrm{P}=0.027)$ (Fig. 1B). To our knowledge, this is the first report that peripheral non-classic monocytes were lower, and classical monocytes level were higher in the migraine population.

\section{Monocytes had a lowered expression of CD36.}

CD36 is a transmembrane protein expressed in various types of cells, including adipocytes, monocytes, macrophages, platelets, endothelial, and muscle cells [23, 24]. This protein belongs to the scavenger receptor $[23,25]$ and binds to lipoproteins, apoptotic cells, and long-chain fatty acids; thus, CD36 is also known as fatty acid translocase $[23,26]$. Coburn et al. demonstrated that long chain fatty acid uptake and utilization have been defective in CD36 knockout mice [27]. Our team reported that a dietary intervention with increased omega-3 fatty acids helped to reduce headache pain [28, 29], and it has been known that omega-3 could induce the CD36 mRNA expression in an animal model [30, 31]. Because of its essential role in lipid metabolism, CD36 MFI expression levels in migraineurs should be studied further. We found that the MFI level of CD36 is significantly lowered in the migraine group (64.92 \pm 35.3$)$ compared with the matched control group (358.25 \pm 197.82$), p=0.031$. (Figure 1C). These results offer another perspective to justify dietary treatment for migraine headaches. Since omega-3 fatty acids can be converted to lipid mediators with antinociceptive properties, this effect could work through inducing the CD36 expression level.

\section{Migraineurs had lower percentage of $\mathrm{CD} 4^{+}$and $\mathrm{CD} 4^{+} \mathrm{CD} 25^{+} \mathrm{T}$ cells in blood.}

It has been reported that the $\mathrm{CD} 4^{+} \mathrm{CD} 25^{+}$regulatory T-cells levels were lowered in migraine patients compared to healthy volunteers [13]. We identified the $\mathrm{CD} 4^{+} \mathrm{CD} 25^{+}$population in this study and display the results in Figure 2A. Compared with the control group, the migraine group had a significantly lower percentage of $\mathrm{CD} 4^{+} \mathrm{CD} 25^{+} \mathrm{T}$ cells (Figure $2 \mathrm{~B}$ ). $\mathrm{CD} 4^{+} \mathrm{CD} 25^{+} \mathrm{T}$ cell percentages in matched control and migraine groups were about $8.3 \%$ and $5.7 \%$ of $C D 3^{+} T$ cells respectively $(p=0.003)$.

The difference between ours and Arumugam's study are in the T cells subsets CD 4 and CD8 cells. In our migraine group, $C D 4^{+} T$ cells were somewhat lower $(p=0.025)$ and $C D 8^{+} T$ cells were slightly higher $(p=0.433)$ in the migraine group compared with the control group (Figure $3 A)$. However, the $C D 4^{+} / C D 8$ ratio change is not significant. (Figure $3 \mathrm{~B}$ ). These results suggest that failure of immunoregulation could play a role in migraine pathophysiology. 


\section{$\mathrm{CD}^{+}{ }^{+}$and $\mathrm{CD}^{+}{ }^{+} \mathrm{T}$ cells had decreased expression of integrin CD18.}

T cell surface integrins can play an important role in cellular adhesion to extracellular matrix and cell signaling. Lymphocyte function-associated antigen 1 (LFA-1) and very late antigen-4 (VLA-4) changes have been linked to migraine attacks [32,33]. LFA-1 is an integrin and belongs to the integrin superfamily of adhesion molecules. Compared with the matched control group, migraine patients' CD18, which is part of the LFA-1, were lower in expression levels measured by mean fluorescence intensity (MFI) on both CD4 T and CD8 T cells, as shown in Figure 4. The CD18 MFI on CD4 helper T cells in matched control and migraine group were 734.5 and 609 , respectively $(p=0.03)$. The CD18 MFI on CD8 killer T cells in matched control and migraine groups were 923.8 and 771.3, respectively $(p=0.005)$ (Figure 4$)$. VLA-4 is an integrin dimer, composed of CD49d and CD29. We found no significant difference in peripheral blood CD49d expression between migraineurs and healthy control (data not shown). Downregulation of the integrins might indicate lymphocyte involvement with transvascular migration.

\section{Cytokine analysis after ex vivo stimulation revealed no significant difference in pro-inflammatory cytokine levels between migraineurs and controls.}

Some proinflammatory cytokines levels increased after migraine attacks [33-35]. To investigate the cytokine production by ex vivo LPS, we used the methods as described in above section, stimulated PBMCs from the recruited patients and control volunteers ex. vivo, nine cytokines (TNF-a, IL-6, IL-10, IL-1 13 , IFN-y, IL-4, IL-17a, IL-12 p70, and IL-21) from supernatant were measured using the R\&D multiplex system. Out of these cytokines, IL-1 $\beta$ and TNF-a were in the readable ranges. No significant differences were detected. (Figure $5 \mathrm{~A}$ and $5 \mathrm{~B}$ ). The sources of cytokine secretion and detection conditions are yet to be investigated in the future.

No other cell populations showed significant differences between migraineurs and the matched controls.

To investigate the peripheral blood leukocytes' changes in migraine patients, we screened the following cell populations, as shown in Table 1. Other than the monocytes and T cell populations, we did not find differences in B cells, NK cells, or dendritic cells between the migraineurs and the control group.

\section{Discussion}

Using peripheral whole blood staining methodology, we found that migraineurs had both myeloid and lymphoid leukocyte surface marker changes compared with the matched control group, which supports the neurogenic inflammatory and autoimmune nature of migraine.

We demonstrated that peripheral blood non-classical monocytes $\left(\mathrm{CD} 14^{+} \mathrm{CD} 16^{++}\right)$in migraine patients were lower than controls. In migraine, triggering factors such as chronic stress, certain foods, hormonal fluctuation, depression and other unknown causes can generate sterile inflammation in CNS and activation of nociceptors [36]. In the presence of these inflammatory stimuli, circulating inflammatory monocytes can quickly migrate into affected tissues, where they differentiate into macrophages and 
dendritic cell subsets [37-39]. The patrolling monocytes localize to the endothelium of vascular inflammatory tissues and release inflammatory mediators $[37,40]$. Patrolling CD $16^{+}$monocytes exhibit long-range crawling over the endothelium of vascular tissues $[17,18]$, and may contribute to the pathogenesis of a wide range of chronic inflammatory diseases, such as obesity, diabetes, atherosclerosis, Chronic Obstructive Pulmonary Disease lung fibrosis, lung cancer, and Alzheimer's disease [41-43]. This population of monocytes can be detected in perivascular circulation; studies have demonstrated decreased levels of nonclassical monocytes in the peripheral blood, as reported in severe forms of lupus nephritis and MS $[15,44]$.

Further, current migraine research has provided some evidence of transmigration of non-classical monocytes to the CNS. Nagata et al. searched biomarkers for migraines using microarray analysis in 2009 [11]. In their report, the expression of 15 genes were altered in migraineurs compared to controls, and one-fifth of these genes were associated with cytoskeleton proteins. It has been reported that human non-classical monocytes exhibit crawling behavior on the endothelium both in vivo and in vitro [16-18, 37, 41]. Non-classical monocytes highly expressed genes associated with cytoskeleton mobility, including Rho GTPase, RHOC and RHOF, and some upstream Rho activators and downstream effectors [16]. These findings are consistent with the Waschbisch clinical study regarding $\mathrm{CD} 16^{+}$monocytes migrating to the CNS in MS [15]. Tension-type headache and migraine without aura are among the most common primary headaches in MS patients [45]. CD16 ${ }^{+}$monocytes play a pivotal role in immune-surveillance of the CNS, and they could migrate to the site of inflammation and contribute to the dysfunction of the BBB and CNS autoimmune disease [15] or NeuroAIDS [46]. Both the monocyte chemokine receptor CXCR7 [46, 47] and the integrity of the BBB play roles in inflammatory migraine pathophysiology $[48,49]$. Due to limitations imposed by the parent RCT, and the small sample size of this affiliated pilot study, we have not investigated the profile of cerebrospinal fluid (CSF) samples. Immune cell profiling in CSF in future studies could provide additional insights into migraine pathogenesis.

In our study, we found significantly lower numbers of nonclassical monocytes and higher numbers of classical monocytes in peripheral blood, as well as significantly lower numbers of the scavenger receptor CD36 in migraineurs. CD36 can bind to three classes of ligands including modified phospholipids, long chain fatty acids and domains of thrombospondin homologs [23]. Broad expression of CD36 on different cells suggests this multi-functional receptor could be involved in a broad spectrum of diseases [23, 5052]. The effects of high dietary omega- 3 and low omega- 6 targeted alteration to treat migraine in the parent randomized clinical trial suggested that the binding of long chain fatty acid to CD36 might play vital roles in chronic headache [28] and possibly for migraine [29]. Indeed, predominant monocytes and platelets gene up-regulations are characteristic for migraine [10]. CD36 binding to domains of thrombospondin homologs and the downstream inflammation activation might play a role in migraine pathophysiology, but the details are still elusive.

Previous research has reported that elevated levels of biomarkers of inflammation are linked to migraine $[5,53,54]$. In the early phase of inflammation, the release of excessive amounts of pro-inflammatory cytokines and lipid-mediators is tied to the pathogenesis of organ dysfunction. Cytokines and 
chemokines are essential molecular and pain mediators in neurovascular inflammation. Some cytokines might play a critical role in the initiation and persistence of pain by activating nociceptive sensory neurons $[55,56]$. The most relevant cytokines related to migraines include IL-1, IL-2, IL-4, IL-6, IL-10, TNF-a, and TGF- $\beta$ [9, 57-59]. In this study, we did not find significant changes of inflammatory cytokines from serum (data not provided) or ex vivo LPS stimulated PBMCs between migraine patients and matched control groups. Although IL- 6 has been reported with higher production from this population in the Koon's study [60], we found a reduced non-classical monocyte population in the peripheral blood, and this is likely to be a reason for not finding significantly increased IL-6 production. Moreover, sample size and condition of ex vivo LPS stimulation needs to be investigated in the future.

Our study also indicated the potential association between migraine and failure of immunoregulation. We detected a significantly lower peripheral blood $\mathrm{CD} 4^{+}$and its subgroup $\mathrm{CD} 4^{+} \mathrm{CD} 25^{+} \mathrm{T}$ cells in the migraine group compared to the matched healthy controls (See Figure 2 and 3). The finding of relatively lower $\mathrm{CD} 4^{+} \mathrm{CD} 25^{+} \mathrm{T}$ cells in migraineurs is consistent with a previous migraine study [13]. In an experimental mouse model of autoimmune encephalomyelitis, non-classical monocytes were shown to be potent suppressors of T cells [61]. Loss of quantity and/or suppressive function of non-classic monocytes may contribute to the development of autoimmune disease. Interestingly, a recent in vitro experiment showed that the $\mathrm{CD} 16^{+}$monocytes, not $\mathrm{CD} 16^{-}$classical monocyte, promoted $\mathrm{CD} 4^{+} \mathrm{T}$ cell trafficking via the endothelial barrier [15]. Provided the $\mathrm{CD}_{16}{ }^{+}$monocytes did migrate to the CNS, they then may enhance T cell entry into the CNS, the latter further facilitating $\mathrm{CD} 16^{+}$monocytes' attachment to the microvasculature and contributing to the breakdown of the BBB. This could explain why peripheral blood $\mathrm{CD} 4^{+} \mathrm{T}$ cell numbers were lower in our study.

T-cell subset and expression of integrins are reduced to potentially facilitate the lymphocyte transmigration to the CNS. LFA-1 is expressed on white blood cells including lymphocytes and other leukocytes and plays a crucial role in the emigration of leukocytes, leaving the bloodstream to enter the tissues. It is a heterodimeric glycoprotein with non-covalently linked subunits alpha (CD11a) and beta (CD18). Empl et al.'s study reported that migraine-with-aura patients had significantly lower LFA-1 expression on both $\mathrm{CD} 4^{+}$and $\mathrm{CD} 8^{+} \mathrm{T}$ cells than that of controls [32]. Sarchielli and colleagues found that LFA -1 on $C D 4^{+}$and $C D 8^{+} T$ cells were progressively down-regulated at two and four hours after migraine attack onset [33]. CD18 expression on blood CD4 and CD8 T cells decreased significantly in migraine patients (Figure 4), which agrees with Empl et al. and Sarchielli and his team's findings, [32, 33] suggesting that migraine may be an inflammatory disease involved with $\mathrm{T}$ lymphocytes trafficking between vascular system and CNS.

There are some limitations in this pilot study. For instance, the sample size was relatively small, and the ex vivo LPS stimulation of PBMC for cytokine production used only a single 24-hour stimulation time point. Because of limited patient samples available from the clinical parent study, CSF samples were not examined. 
In summary, we observed that the percentage of peripheral non-classical monocyte $\left(\mathrm{CD} 14^{+} \mathrm{CD} 16^{++}\right)$in migraine is lower than in controls, suggesting possible migration of the $\operatorname{CD} 14^{+} \mathrm{CD} 16^{++}$population into the endothelium of cranial vessels. This migration potentially plays a role in releasing inflammatory mediators, leading to migraine pathogenesis. Future research regarding the levels of non-classic monocyte population in the CNS (for example, in cerebrospinal fluid) would be of interest to confirm the potential migration of the $\mathrm{CD}_{16}{ }^{+}$monocyte population. Migraineurs' reduced monocyte CD36 expression suggests the potential mechanism of targeted high dietary omega-3 fatty acid treatment. Migraine appears to be an inflammatory disease with a lowered $C D 4^{+} T$ cell population, specifically a lower $\mathrm{CD} 4^{+} \mathrm{CD} 25^{+} \mathrm{T}$ cell population, as well as lower adhesion molecule $\mathrm{CD} 18$ levels on $\mathrm{T}$ cells compared to non-migraine controls. These preliminary findings need to be confirmed with studies conducted on a larger sample size of patients with migraine.

If future studies can directly confirm the migration of the non-classical monocytes in the CNS of migraine patients, potential therapeutic strategies may be broadened. For example, since CD16 ${ }^{+}$monocytes express CXCR7 on cell surface; using CXCR7 antagonist might help reduce the non-classical monocytes transmigration across the BBB [46]. This study also provides additional evidence for the use of targeted alterations in dietary linolenic acid and n-3 EPA ${ }^{+}$DHA in migraineurs[28, 29].

\section{Conclusions}

Our results demonstrated that migraine is associated with dysregulated peripheral immune homeostasis that may play a role in its pathophysiology.

\section{Abbreviations}

BBB

blood brain barrier

$\mathrm{BMI}$

body mass index

CNS

central nervous system

LFA-1

Lymphocyte function-associated antigen 1

MFI

mean fluorescence intensity

MS

multiple sclerosis

PBMC

peripheral blood mononuclear cells

PMNs 
Polymorphonuclear leukocytes

VLA-4

very late antigen-4

n-3

Omega-3

\section{Declarations}

\section{AUTHORSHIP}

H.L. designed the experiments, performed the experiments, and was the primary author of this manuscript. Q.F. contributed to experimental design, data processing, and statistical analysis. K.P. recruited and consented to the control group, performed experiments with H.L., and critically revised this manuscript. Y.S. processed the flow cytometry raw data, statistical analysis, and generated related graphs. K.R.F. was involved with the NC TraCS $2 \mathrm{k}$ grant application and data analysis. S.G. and J.D.M. participated in editing the manuscript and management of the NIH T-32 fellowship grant NCCIH 5T32AT003378.

\section{ACKNOWLEDGMENTS}

The parent grant funded by NIH NCCIH R01-AT007813 (2013-2018) was awarded to Dr. John D. Mann as principal investigator at the UNC School of Medicine, Chapel Hill, NC. The study was financially supported by NIH NCCIH 5T32AT003378 (H.L.) and NC TraCS2K from UNC Translational and Clinical Science Institute award 2KR691507 (H.L.). The postdoctoral office location was at the Program on Integrative Medicine, Department of Physical Medicine and Rehabilitation, UNC School of Medicine, Chapel Hill, NC. The benchwork was conducted in Dr. Lishan Su's laboratory at the Department of Microbiology and Immunology, School of Medicine, UNC-Chapel Hill. Dr. Guangming Li offered generous technical support. Dr. Can Cui helped set up the strategy for the FlowJo analysis. Drs. Xuewei Zhu, Christopher Ramsden, Lishan Su, and Peng Liu generously helped with proofreading the manuscript. Ms. Theresa Watson from St. Mary-of-the-Woods College helped with figure editing.

\section{DISCLOSURES}

The authors declare no conflict of interest. The contents of this publication are solely the responsibility of the authors and so not represent the official views and opinions of the $\mathrm{NIH}$.

\section{References}

1. Stovner LJ, Hagen K, Jensen R, Katsarava Z, Lipton RB, Scher Al, et al. The global burden of headache: a documentation of headache prevalence and disability worldwide. Cephalalgia. 2007;27 3:193-210; doi: 10.1111/j.1468-2982.2007.01288.x. 
2. Mann JD, Faurot KR, Maclntosh B, Palsson OS, Suchindran CM, Gaylord SA, et al. A sixteen-week three-armed, randomized, controlled trial investigating clinical and biochemical effects of targeted alterations in dietary linoleic acid and n-3 EPA+DHA in adults with episodic migraine: Study protocol. Prostaglandins Leukot Essent Fatty Acids. 2018;128:41-52; doi: 10.1016/j.plefa.2017.11.002.

3. Williamson DJ, Hargreaves RJ. Neurogenic inflammation in the context of migraine. Microsc Res Tech. 2001;53 3:167-78; doi: 10.1002/jemt.1081.

4. Waeber C, Moskowitz MA. Migraine as an inflammatory disorder. Neurology. 2005;64 10 suppl 2:S9-S15; doi: 10.1212/WNL.64.10_suppl_2.S9.

5. Tietjen GE, Khubchandani J, Herial N, Palm-Meinders IH, Koppen H, Terwindt GM, et al. Migraine and vascular disease biomarkers: A population-based case-control study. Cephalalgia. 2017:333102417698936; doi: 10.1177/0333102417698936.

6. Mahajan R, Mahajan R, Juneja A, Anand K. Inflammatory biomarkers in migraine- A prospective observational study. International Journal of Scientific Research. 2020.

7. Sarıcam G. Relationship between migraine headache and hematological parameters. Acta Neurol Belg. 2020.

8. Kemper RH, Meijler WJ, Korf J, Ter Horst GJ. Migraine and function of the immune system: a metaanalysis of clinical literature published between 1966 and 1999. Cephalalgia. 2001;21 5:549-57; doi: 10.1046/j.1468-2982.2001.00196.x.

9. Bruno PP, Carpino F, Carpino G, Zicari A. An overview on immune system and migraine. Eur Rev Med Pharmacol Sci. 2007;11 4:245-8.

10. Du X, Tang Y, Xu H, Lit L, Walker W, Ashwood P, et al. Genomic profiles for human peripheral blood T cells, B cells, natural killer cells, monocytes, and polymorphonuclear cells: Comparisons to ischemic stroke, migraine, and Tourette syndrome. Genomics. 2006;87 6:693-703; doi: http://dx.doi.org/10.1016/j.ygeno.2006.02.003.

11. Nagata E, Hattori H, Kato M, Ogasawara S, Suzuki S, Shibata M, et al. Identification of biomarkers associated with migraine with aura. Neurosci Res. 2009;64 1:104-10; doi: 10.1016/j.neures.2009.02.001.

12. Gerring ZF, Powell JE, Montgomery GW, Nyholt DR. Genome-wide analysis of blood gene expression in migraine implicates immune-inflammatory pathways. Cephalalgia. 2017:333102416686769; doi: 10.1177/0333102416686769.

13. Arumugam $M$, Parthasarathy $V$. Reduction of $C D 4+C D 25+$ regulatory T-cells in migraine: Is migraine an autoimmune disorder? J Neuroimmunol. 2016;290:54-9; doi: http://dx.doi.org/10.1016/j.jneuroim.2015.11.015. 
14. Sampath P, Moideen K, Ranganathan UD, Bethunaickan R. Monocyte Subsets: Phenotypes and Function in Tuberculosis Infection. Frontiers in Immunology. 2018;9 1726; doi:

10.3389/fimmu.2018.01726.

15. Waschbisch A, Schroder S, Schraudner D, Sammet L, Weksler B, Melms A, et al. Pivotal Role for CD16+ Monocytes in Immune Surveillance of the Central Nervous System. J Immunol. 2016;196 4:155867; doi: 10.4049/jimmunol.1501960.

16. Wong KL, Yeap WH, Tai JJY, Ong SM, Dang TM, Wong SC. The three human monocyte subsets: implications for health and disease. Immunol Res. 2012;53 1:41-57; doi: 10.1007/s12026-012-8297-3.

17. Auffray C, Sieweke MH, Geissmann F. Blood Monocytes: Development, Heterogeneity, and Relationship with Dendritic Cells. Annu Rev Immunol. 2009;27 1:669-92; doi: doi:10.1146/annurev.immunol.021908.132557.

18. Saha P, Geissmann F. Toward a functional characterization of blood monocytes. Immunol Cell Biol. 2011;89 1:2-4.

19. Veenstra M, León-Rivera R, Li M, Gama L, Clements JE, Berman JW. Mechanisms of CNS Viral Seeding by HIV+ CD14+ CD16+ Monocytes: Establishment and Reseeding of Viral Reservoirs Contributing to HIV-Associated Neurocognitive Disorders. mBio. 2017;8 5:e01280-17; doi: 10.1128/mBio.01280-17.

20. van Sleen $Y$, Wang Q, van der Geest KSM, Westra J, Abdulahad WH, Heeringa P, et al. Involvement of Monocyte Subsets in the Immunopathology of Giant Cell Arteritis. Scientific reports. 2017;7 1:6553-; doi: 10.1038/s41598-017-06826-4.

21. Nicholson JK, Rao PE, Calvelli T, Stetler-Stevenson M, Browning SW, Yeung L, et al. Artifactual staining of monoclonal antibodies in two-color combinations is due to an immunoglobulin in the serum and plasma. Cytometry. 1994;18 3:140-6; doi: 10.1002/cyto.990180305.

22. Mukherjee R, Kanti Barman P, Kumar Thatoi P, Tripathy R, Kumar Das B, Ravindran B. NonClassical monocytes display inflammatory features: Validation in Sepsis and Systemic Lupus Erythematous. Scientific Reports. 2015;5 1:13886; doi: 10.1038/srep13886.

23. Choromańska B, Myśliwiec P, Choromańska K, Dadan J, Chabowski A. The role of CD36 receptor in the pathogenesis of atherosclerosis. Adv Clin Exp Med. 2017;26 4:717-22; doi: 10.17219/acem/62325.

24. Laugerette F, Passilly-Degrace P, Patris B, Niot I, Febbraio M, Montmayeur J-P, et al. CD36 involvement in orosensory detection of dietary lipids, spontaneous fat preference, and digestive secretions. The Journal of Clinical Investigation. 2005;115 11:3177-84; doi: 10.1172/JCl25299.

25. Xie S, Lee YF, Kim E, Chen LM, Ni J, Fang LY, et al. TR4 nuclear receptor functions as a fatty acid sensor to modulate CD36 expression and foam cell formation. Proc Natl Acad Sci U S A. 2009;106 32:13353-8; doi: 10.1073/pnas.0905724106. 
26. Zheng JS, Chen J, Wang L, Yang H, Fang L, Yu Y, et al. Replication of a Gene-Diet Interaction at CD36, NOS3 and PPARG in Response to Omega-3 Fatty Acid Supplements on Blood Lipids: A DoubleBlind Randomized Controlled Trial. EBioMedicine. 2018;31:150-6; doi: 10.1016/j.ebiom.2018.04.012.

27. Coburn CT, Knapp FF, Jr., Febbraio M, Beets AL, Silverstein RL, Abumrad NA. Defective uptake and utilization of long chain fatty acids in muscle and adipose tissues of CD36 knockout mice. J Biol Chem. 2000;275 42:32523-9; doi: 10.1074/jbc.M003826200.

28. Ramsden CE, Faurot KR, Zamora D, Suchindran CM, Macintosh BA, Gaylord S, et al. Targeted alteration of dietary n-3 and n-6 fatty acids for the treatment of chronic headaches: a randomized trial. Pain. 2013;154 11:2441-51; doi: 10.1016/j.pain.2013.07.028.

29. Ramsden CE, Zamora D, Faurot KR, Maclntosh B, Horowitz M, Keyes GS, et al. Dietary alteration of $\mathrm{n}-3$ and $\mathrm{n}-6$ fatty acids for headache reduction in adults with migraine: randomized controlled trial. BMJ. 2021;374:n1448; doi: 10.1136/bmj.n1448.

30. Yuan F, Wang H, Tian Y, Li Q, He L, Li N, et al. Fish oil alleviated high-fat diet-induced non-alcoholic fatty liver disease via regulating hepatic lipids metabolism and metaflammation: a transcriptomic study. Lipids Health Dis. 2016;15:20; doi: 10.1186/s12944-016-0190-y.

31. Alexander Aguilera A, Hernández Díaz G, Lara Barcelata M, Angulo Guerrero O, Oliart Ros RM. Induction of Cd36 expression elicited by fish oil PUFA in spontaneously hypertensive rats. The Journal of Nutritional Biochemistry. 2006;17 11:760-5; doi: https://doi.org/10.1016/j.jnutbio.2005.12.007.

32. Empl M, Sostak P, Breckner M, Riedel M, Muller N, Gruber R, et al. T-cell subsets and expression of integrins in peripheral blood of patients with migraine. Cephalalgia. 1999;19 8:713-7; discussion 697; doi: 10.1046/j.1468-2982.1999.019008713.x.

33. Sarchielli P, Alberti A, Baldi A, Coppola F, Rossi C, Pierguidi L, et al. Proinflammatory Cytokines, Adhesion Molecules, and Lymphocyte Integrin Expression in the Internal Jugular Blood of Migraine Patients Without Aura Assessed Ictally. Headache: The Journal of Head and Face Pain. 2006;46 2:200-7; doi: 10.1111/j.1526-4610.2006.00337.x.

34. Kothur K, Wienholt L, Brilot F, Dale RC. CSF cytokines/chemokines as biomarkers in neuroinflammatory CNS disorders: A systematic review. Cytokine. 2016;77:227-37; doi: https://doi.org/10.1016/j.cyto.2015.10.001.

35. Vezzani A, Viviani B. Neuromodulatory properties of inflammatory cytokines and their impact on neuronal excitability. Neuropharmacology. 2015;96:70-82; doi:

https://doi.org/10.1016/j.neuropharm.2014.10.027.

36. Ramachandran R. Neurogenic inflammation and its role in migraine. Seminars in Immunopathology. 2018;40 3:301-14; doi: 10.1007/s00281-018-0676-y. 
37. Thomas G, Tacke R, Hedrick CC, Hanna RN. Nonclassical patrolling monocyte function in the vasculature. Arterioscler Thromb Vac Biol. 2015;35 6:1306-16; doi: 10.1161/atvbaha.114.304650.

38. Italiani P, Boraschi D. From Monocytes to M1/M2 Macrophages: Phenotypical vs. Functional Differentiation. Frontiers in Immunology. 2014;5:514; doi: 10.3389/fimmu.2014.00514.

39. Martinez FO, Gordon S. The M1 and M2 paradigm of macrophage activation: time for reassessment. F1000Prime Reports. 2014;6:13; doi: 10.12703/P6-13.

40. Abdulkhaleq LA, Assi MA, Abdullah R, Zamri-Saad M, Taufiq-Yap YH, Hezmee MNM. The crucial roles of inflammatory mediators in inflammation: A review. Veterinary world. 2018;11 5:627-35; doi: 10.14202/vetworld.2018.627-635.

41. Kapellos TS, Bonaguro L, Gemünd I, Reusch N, Saglam A, Hinkley ER, et al. Human Monocyte Subsets and Phenotypes in Major Chronic Inflammatory Diseases. Frontiers in immunology. 2019;10:2035-; doi: 10.3389/fimmu.2019.02035.

42. Min D, Brooks B, Wong J, Salomon R, Bao W, Harrisberg B, et al. Alterations in Monocyte CD16 in Association with Diabetes Complications. Mediators Inflamm. 2012;2012:649083; doi: 10.1155/2012/649083.

43. Narasimhan PB, Marcovecchio P, Hamers AAJ, Hedrick CC. Nonclassical Monocytes in Health and Disease. Annu Rev Immunol. 2019;37 1:439-56; doi: 10.1146/annurev-immunol-042617-053119.

44. Barrera García A, Gómez-Puerta JA, Arias LF, Burbano C, Restrepo M, Vanegas AL, et al. Infiltrating CD16+ Are Associated with a Reduction in Peripheral CD14+CD16++ Monocytes and Severe Forms of Lupus Nephritis. Autoimmune Diseases. 2016;2016:9324315; doi: 10.1155/2016/9324315.

45. La Mantia L, Prone V. Headache in multiple sclerosis and autoimmune disorders. Neurol Sci. 2015;36 Suppl 1:75-8; doi: 10.1007/s10072-015-2146-9.

46. Veenstra M, Williams DW, Calderon TM, Anastos K, Morgello S, Berman JW. Frontline Science: CXCR7 mediates CD14+CD16+ monocyte transmigration across the blood brain barrier: a potential therapeutic target for NeuroAIDS. J Leukoc Biol. 2017;102 5:1173-85; doi: 10.1189/jlb.3HI0517-167R.

47. Chatterjee M, von Ungern-Sternberg SNI, Seizer P, Schlegel F, Büttcher M, Sindhu NA, et al. Plateletderived CXCL12 regulates monocyte function, survival, differentiation into macrophages and foam cells through differential involvement of CXCR4-CXCR7. Cell Death \& Disease. 2015;6 11:e1989-e; doi: 10.1038/cddis.2015.233.

48. Goadsby PJ, Holland PR, Martins-Oliveira M, Hoffmann J, Schankin C, Akerman S. Pathophysiology of Migraine: A Disorder of Sensory Processing. Physiol Rev. 2017;97 2:553-622; doi: 10.1152/physrev.00034.2015. 
49. DosSantos MF, Holanda-Afonso RC, Lima RL, DaSilva AF, Moura-Neto V. The role of the bloodbrain barrier in the development and treatment of migraine and other pain disorders. Front Cell Neurosci. 2014;8:302; doi: 10.3389/fncel.2014.00302.

50. Febbraio M, Silverstein RL. CD36: Implications in Cardiovascular Disease. The international journal of biochemistry \& cell biology. 2007;39 11:2012-30; doi: 10.1016/j.biocel.2007.03.012.

51. Kennedy DJ, Kuchibhotla S, Westfall KM, Silverstein RL, Morton RE, Febbraio M. A CD36dependent pathway enhances macrophage and adipose tissue inflammation and impairs insulin signalling. Cardiovasc Res. 2011;89 3:604-13.

52. Sharif O, Matt U, Saluzzo S, Lakovits K, Haslinger I, Furtner T, et al. The scavenger receptor CD36 downmodulates the early inflammatory response while enhancing bacterial phagocytosis during pneumococcal pneumonia. J Immunol. 2013;190 11:5640-8; doi: 10.4049/jimmunol.1202270.

53. Gormley P, Winsvold BS, Nyholt DR, Kallela M, Chasman DI, Palotie A. Migraine genetics: from genome-wide association studies to translational insights. Genome Med. 2016;8 1:86; doi: 10.1186/s13073-016-0346-4.

54. Khaiboullina SF, Mendelevich EG, Shigapova LH, Shagimardanova E, Gazizova G, Nikitin A, et al. Cerebellar Atrophy and Changes in Cytokines Associated with the CACNA1A R583Q Mutation in a Russian Familial Hemiplegic Migraine Type 1 Family. Front Cell Neurosci. 2017;11:263; doi: 10.3389/fncel.2017.00263.

55. Zhang J-M, An J. Cytokines, inflammation, and pain. Int Anesthesiol Clin. 2007;45 2:27-37; doi: 10.1097/AIA.0b013e318034194e.

56. Patti F, Nicoletti A, Pappalardo A, Castiglione A, Lo Fermo S, Messina S, et al. Frequency and severity of headache is worsened by Interferon- $\beta$ therapy in patients with multiple sclerosis. Acta Neurol Scand. 2012;125 2:91-5; doi: 10.1111/j.1600-0404.2011.01532.x.

57. Franceschini A, Vilotti S, Ferrari MD, van den Maagdenberg AMJM, Nistri A, Fabbretti E. TNFa levels and macrophages expression reflect an inflammatory potential of trigeminal ganglia in a mouse model of familial hemiplegic migraine. PloS one. 2013;8 1:e52394-e; doi: 10.1371/journal.pone.0052394.

58. Martelletti P, Zicari A, Realacci M, Fiore G, De Filippis S, Stirparo G, et al. Expression of NOS-2, COX-2 and Th1/Th2 cytokines in migraine. The Journal of Headache and Pain. 2001;2 Suppl 1:s51-s6; doi: $10.1007 /$ s101940170010.

59. Munno I, Centonze V, Marinaro M, Bassi A, Lacedra G, Causarano V, et al. Cytokines and Migraine: Increase of IL-5 and IL-4 Plasma Levels. Headache: The Journal of Head and Face Pain. 1998;38 6:465-7; doi: 10.1046/j.1526-4610.1998.3806465.x. 
60. Kong BS, Kim Y, Kim GY, Hyun J-W, Kim S-H, Jeong A, et al. Increased frequency of IL-6-producing non-classical monocytes in neuromyelitis optica spectrum disorder. Journal of Neuroinflammation. 2017;14 1:191; doi: 10.1186/s12974-017-0961-z.

61. Slaney CY, Toker A, La Flamme A, Bäckström BT, Harper JL. Naïve blood monocytes suppress Tcell function. A possible mechanism for protection from autoimmunity. Immunol Cell Biol. 2011;89 1:7-13; doi: $10.1038 /$ icb.2010.110.

\section{Tables 1-2}

Table 1

\begin{tabular}{|llllll|}
\hline \multicolumn{2}{|l}{$\begin{array}{l}\text { Monocyte, its subsets and } \\
\text { activation markers }\end{array}$} & \multicolumn{2}{l|}{$\begin{array}{l}\text { NK, T cells, their subsets and } \\
\text { activation markers }\end{array}$} & \multicolumn{2}{l|}{$\begin{array}{l}\text { B, Dendritic cells, their subsets } \\
\text { and activation markers }\end{array}$} \\
\hline CD3 & APC-H7 & CD8 & V500 & CD3 & APC-H7 \\
\hline CD36 & PerCP-Cy5.5 & CD4 & PerCP-Cy5.5 & CD4 & PerCP-Cy5.5 \\
\hline CD14 & V500 & CD3 & APC-H7 & CD11C & BV510 \\
\hline CD16 & BV421 & CD16 & BV421 & HLA-DR & BB515 \\
\hline HLD-DR & BB515 & CD25 & BB515 & CD123 & BV421 \\
\hline CD56 & PE-Cy7 & CD18 & PE & CD86 & APC \\
\hline CD86 & APC & CD56 & PE-Cy7 & CD19 & PE-Cy7 \\
\hline CD163 & PE & CD49d & APC & CD80 & PE \\
\hline
\end{tabular}

Table 2 
Migraine sample Controls

\begin{tabular}{|c|c|c|}
\hline Male gender* & $3(20 \%)$ & $3(20 \%)$ \\
\hline Age $^{\star}$ & $39.3(12.2)$ & $39.7(12.2)$ \\
\hline Body Mass Index* & $27.2(4.6)$ & $27.4(4.8)$ \\
\hline \multicolumn{3}{|l|}{ Race/ethnicity } \\
\hline NonHispanic White & $12(80 \%)$ & $10(67 \%)$ \\
\hline NonHispanic Black & $2(13 \%)$ & $2(13 \%)$ \\
\hline Other** & $1(7 \%)$ & $3(20 \%)$ \\
\hline \multicolumn{3}{|l|}{ Education } \\
\hline High school or less & $3(20 \%)$ & $0(0 \%)$ \\
\hline Some college & $2(13 \%)$ & $5(38 \%)$ \\
\hline Bachelor's degree & $5(33 \%)$ & $4(31 \%)$ \\
\hline Advanced degree & $5(33 \%)$ & $4(31 \%)$ \\
\hline \multicolumn{3}{|l|}{ Income } \\
\hline$\$ 20,000$ or less & $1(7 \%)$ & $0(0 \%)$ \\
\hline$\$ 21,000-40,000$ & $1(7 \%)$ & $4(29 \%)$ \\
\hline$\$ 41,000-60,000$ & $2(13 \%)$ & $4(29 \%)$ \\
\hline$\$ 61,000-80,000$ & $2(13 \%)$ & $3(21 \%)$ \\
\hline More than $\$ 80,000$ & $7(47 \%)$ & $3(21 \%)$ \\
\hline \multicolumn{3}{|l|}{ Relationship status } \\
\hline Living with partner & $12(80 \%)$ & $7(50 \%)$ \\
\hline Not living with partner & $3(20 \%)$ & $7(50 \%)$ \\
\hline \multicolumn{3}{|l|}{ Smoking status } \\
\hline Current smoker & $1(7 \%)$ & $0(0 \%)$ \\
\hline Former smoker & $4(27 \%)$ & $3(21 \%)$ \\
\hline Nonsmoker & $10(67 \%)$ & $11(79 \%)$ \\
\hline \multicolumn{3}{|l|}{ Alcohol intake } \\
\hline None or rare & $13(87 \%)$ & $10(71 \%)$ \\
\hline Occasional & $2(13 \%)$ & $4(29 \%)$ \\
\hline
\end{tabular}


Continuous variables presented as mean (standard deviation)

Categorical variables presented as $\mathrm{n}(\%)$

* Matching variables

** Other race $=$ Asian, multiple races, or unreported

\section{Figures}

\section{Figure 1}

Legend not included with this version

Figure 2

Legend not included with this version

Figure 3

Legend not included with this version

Figure 4

Legend not included with this version

\section{Figure 5}

Legend not included with this version

\section{Supplementary Files}

This is a list of supplementary files associated with this preprint. Click to download. 
- Table3.docx

Page 20/20 